\title{
Telomerase activity in gestational trophoblastic disease
}

\author{
A N Y Cheung, D K Zhang, Y Liu, H Y S Ngan, D H Shen, S W Tsao
}

\begin{abstract}
Aims-To investigate the pattern of telomerase activity in hydatidiform mole as compared with normal placenta and choriocarcinoma, and to determine the prognostic significance of telomerase activity in hydatidiform mole.

Methods-Telomerase activity in 35 cases of hydatidiform mole, 35 normal placentas, one choriocarcinoma sample, and two choriocarcinoma cell lines (JAR, JEG3) was determined using the sensitive polymerase chain reaction based telomeric repeat amplification protocol (TRAP) assay. Two cases of breast carcinoma and two cases of ovarian carcinoma were also included as positive controls in the telomerase assay.

Results-Telomerase activity was detected in 11 of 30 early placentas $(36.7 \%)$, one of five term placentas $(20 \%)$, five of 27 hydatidiform moles which regressed spontaneously (18.5\%), and six of eight hydatidiform moles which developed persistent trophoblastic disease $\mathbf{( 7 5 \% )}$ (including three which developed metastases). Hydatidiform moles which subsequently developed persistent disease, especially those which metastasised, were more likely to express telomerase activity $(\mathrm{p}<0.01)$. However, there was no significant difference in the frequency of telomerase activity between early placentas and hydatidiform mole. Strong telomerase activity was observed in choriocarcinoma tissue, choriocarcinoma cell lines, and ovarian and breast carcinomas.

Conclusions-Telomerase activation occurs in hydatidiform mole with a similar incidence to early normal placentas. This supports the concept that hydatidiform mole is essentially an abnormal conceptus. There is an association between telomerase activation and the development of persistent trophoblastic disease. Further study is warrant to confirm the prognostic significance of telomerase activity in hydatidiform mole. (f Clin Pathol 1999;52:588-592)
\end{abstract}

Keywords: telomerase activity; gestational trophoblastic disease; hydatidiform mole

Correspondence to: Dr S W Tsao, Department of Anatomy, Faculty of Medicine, University of Hong Kong, Rm 5-12, Li Shu Fan Building, 5 Sassoon Road, Hong Kong. email:

gswtsao@hkucc.hku.hk

Accepted for publication 21 April 1999 sequences is associated with cell division ow to the end replication problem involved in DNA replication. Telomerase is a special type
Repetitive telomere sequences are present at the ends of eukaryotic chromosomes which protect the ends from damage and rearrange- of reverse transcriptase which stabilises the telomeric ends of human chromosomes by adding the TTAGGG repeats onto the chromosome ends. Most normal somatic cells lack telomerase activity, and successive cell division will result in progressive shortening of telomeres leading to chromosomal instability. Telomere shortening, both in vivo and in vitro, has been postulated to be the mitotic clock counting the number of mitoses that the cells have undertaken. Excessive shortening of telomeric length may trigger the onset of cell senescence. The telomeres of tumour cells have to be maintained in order to sustain their continuous proliferative capacities, and telomerase is commonly activated in human tumours for this purpose. $^{12}$

The placenta is a dynamic organ with programmed proliferation and differentiation of trophoblasts whose proper function is important for maintaining a successful pregnancy. Abnormal proliferation of trophoblasts may result in gestational trophoblastic disease which encompasses a heterogeneous group of lesions including hydatidiform mole, choriocarcinoma, and placental site trophoblastic tumour. ${ }^{3}$ These lesions are unique, since they can be considered as allografts arising from a conceptus that invades the maternal tissues.

Significant differences in morphology and clinical behaviour have been documented in these closely related entities. Some of these lesions, such as choriocarcinoma and placental site trophoblastic tumour, are definitely neoplastic, while hydatidiform moles may just be abnormal placentas that are prone to malignant transformation. Hydatidiform mole is diagnosed histologically by the presence of hydropic swelling of the chorionic villi and proliferation of the trophoblasts. It is associated with a substantial risk (10-15\%) of developing persistent gestational trophoblastic disease and may even develop into choriocarcinoma eventually. The mechanisms involved in the pathogenesis and progression of hydatidiform mole are poorly understood. Except for the serial assays of serum and urine human chorionic gonadotrophin (hCG), there is no reliable predictor for the early detection of persistent trophoblastic disease.

In this study, we assessed and compared telomerase activity in normal placenta of different gestational stages, hydatidiform mole, and choriocarcinoma using the telomeric repeat amplification protocol (TRAP) assay. ${ }^{5-7}$ The significance of telomerase activity in the development of normal placenta and pathogenesis of gestational trophoblastic disease was investigated. We are particularly interested in hyda- 
tidiform moles with the potential to produce invasive or even metastatic disease. Such malignant potential may be accompanied by the immortalisation of the trophoblasts in the hydatidiform mole, and this could involve activation of telomerase. The level of telomerase activity was also correlated with clinical follow up to see if high telomerase activity is associated with the development of persistent trophoblastic disease.

\section{Methods}

CLINICAL SAMPLES

Thirty five clinically and ultrasonographically suspected cases of hydatidiform mole were suction evacuated. Their gestational age ranged from six to 22 weeks. Thirty placentas of gestational age ranging from six to 20 weeks and five term placentas were obtained after induced abortion by suction evacuation or normal delivery. Fresh chorionic villi and molar vesicles were dissected, selected, snap frozen in liquid nitrogen, and stored at $-70^{\circ} \mathrm{C}$. The rest of the tissue was fixed in formalin. Thirty two of the 35 hydatidiform moles were complete while the other three were partial. Distinction between complete and partial hydatidiform moles was by histological examination using well established diagnostic criteria $^{34}$ and in situ hybridisation. For confirmation of complete and partial moles by in situ hybridrisation, biotinylated probes specific for the pericentromeric regions of chromosomes 16 and $\mathrm{X}$, as well as part of chromosome Y (American Type Culture Collection, Rockville, Maryland, USA), were used on formalin fixed paraffin embedded tumour tissues. ${ }^{8}$ The clinical records of patients with a diagnosis of hydatidiform mole, including the postevacuation hCG levels and administration of chemotherapy, were retrieved for assessment.

One case of choriocarcinoma, two choriocarcinoma cell lines (JAR and JEG3; American Type Culture Collection), two cases of breast carcinoma, and two cases of ovarian cystadenocarcinoma were also included in the study. The HeLa cell line (cervical cancer) was used as internal positive control for telomerase assay to adjust for interassay variation.

\section{EXTRACTION OF TELOMERASE}

Telomerase was extracted from sections of the frozen tissues or cell pellets according to a previously published protocol. ${ }^{6}$ Briefly, each frozen section or cell pellet was extracted with 20 to $50 \mu \mathrm{l}$ of ice cold lysis buffer. The components of the lysis buffer were $10 \mathrm{mM}$ Tris- $\mathrm{HCl}$ ( $\mathrm{pH} 7.5$ ), $1 \mathrm{mM} \mathrm{MgCl}_{2}$, 1 M EGTA, $0.1 \mathrm{mM}$ phenylmethylsulphonyl fluoride, $5 \mathrm{mM} \beta$-mercaptoethanol, $0.5 \%$ 3-[(3-cholamidopropyl) dimethylamino]-1propane sulphonate (Sigma), and 10\% glycerol. All precautions against RNase contamination were observed. Frozen tissues or cell pellets were homogenised in the cold lysis buffer with disposable pestles and incubated on ice for 30 minutes. The homogenised lysate was centrifuged at $14000 \mathrm{~g}$ for 30 minutes at $4^{\circ} \mathrm{C}$ and aliquots of the supernatant were stored frozen at $-80^{\circ} \mathrm{C}$ until use. The telomerase activity in the extract was then assessed by the telomeric repeat amplification protocol (TRAP)..$^{5-7}$

TELOMERASE ASSAY - TELOMERIC REPEAT

AMPLIFICATION PROTOCOL (TRAP)

Telomerase activity was detected by its ability to add repeats of TTAGGG to its substrate (TS primer) which is an oligonucleotide (5'AATCCGTCGAGCAGAGTT3'). This is a two step reaction. The telomerase present in the extracts would extend the TS primer to generate an extended product. The telomerase product generated was then amplified by polymerase chain reaction (PCR) by including the reverse primer (5'-CCCTTACCCTTACC CTTA CCCTTAA-3') in the reaction.

Details of the TRAP assay have been described previously. ${ }^{67}$ The assay tubes were prepared by sequestering $0.1 \mu \mathrm{g}$ of CX primer (5'-CCCTTACCCTTA-CCCTTACCCTTAA-3') under a wax barrier (Ampliwax; Perkin Elmer Cetus). Each extract was assayed in $25 \mu \mathrm{l}$ of reaction mixture containing $20 \mathrm{mM}$ Tris$\mathrm{HCl}$ ( $\mathrm{pH} 8.0$ ), $1.5 \mathrm{mM} \mathrm{MgCl}, 60 \mathrm{mM} \mathrm{KCl}$, $0.05 \%$ Tween 20, 1 mM EGTA, $50 \mu \mathrm{M}$ deoxynucleotide triphosphates, $0.1 \mu \mathrm{g}$ of TS primer (5'-AATCCGTCGAGCAGAGTT-3'), $0.5 \mu \mathrm{M}$ of T4 gene 32 protein (Boehringer Mannheim), $2 \mu \mathrm{Ci}$ of $\left[\alpha{ }^{32} \mathrm{P}\right] \mathrm{dCTP}(3000 \mathrm{Ci} / \mathrm{mmol}$; Amersham International), and 1.0 unit of Taq DNA polymerase (Boehringer Mannheim). A 30 minute incubation period at room temperature was allowed for the telomerase mediated extension of the TS primer. The reaction mixture was then heated at $94^{\circ} \mathrm{C}$ for three minutes and subjected to $31 \mathrm{PCR}$ cycles $\left(94^{\circ} \mathrm{C}\right.$ for 30 seconds, $50^{\circ} \mathrm{C}$ for 30 seconds, and $72^{\circ} \mathrm{C}$ for 45 seconds). The PCR products were then electrophoresed on a $15 \%$ polyacrylamide gel. To ensure the specificity of the telomerase assay, RNase pretreatment of the telomerase extract $(0.5 \mu \mathrm{g}$ of RNase A for 30 minutes at $37^{\circ} \mathrm{C}$ ) was always included for every sample examined. Only RNase sensitive activities were scored as telomerase activities.

The telomerase activity in each extract was assayed at three concentrations $(3 \mu \mathrm{g}, 0.3 \mu \mathrm{g}$, and $0.03 \mu \mathrm{g}$ per reaction. The dilution allowed a semiquantitative evaluation of telomerase activity in the extract. In addition, the presence of telomerase inhibitor in the extract might be diluted, allowing telomerase activity to be detected at a lower concentration of inhibitor. The specificity of the TRAP assay was ensured by the disappearance of the six base pairs (bp) laddering signals after treatment with RNase. For cases with negative telomerase activities, the assay was repeated with the TRAPeze kit (Oncor) with the inclusion of $36 \mathrm{bp}$ internal control in each reaction. This is to confirm that the telomerase negative samples detected were true negatives rather than resulting from the presence of PCR inhibitors in the TRAP assay. The HeLa cell extract was also included in each telomerase assay as a positive telomerase control to adjust for interassay variation.

We examined the telomerase activity of different stages of normal placenta, hydatidiform mole, choriocarcinoma sample and cell 
lines, as well as the breast and ovarian carcinomas. Telomerase activity of the hydatidiform mole was correlated with the clinical outcome of the patients.

\section{Results}

Among the 35 hydatidiform moles studied, which included 32 complete moles and three partial moles, 27 regressed spontaneously. Eight of the patients had persistently raised hCG level with a diagnosis of persistent trophoblastic disease. Four of these eight patients had documented metastases.

Figure 1 shows the telomerase activities detected in various trophoblastic tissues and a choriocarcinoma cell line (JAR) by the TRAPeze kit. There were apparent variations of telomerase activities detected in different trophoblastic tissues. Strong telomerase was detected in JAR cells. Comparatively weaker telomerase activity was detected in case 31 , which was a first trimester placenta, and in case 29 which was a complete mole. No telomerase activity was detected in case 30, which was also a complete mole. There were variations in the level of telomerase detected among individual trophoblastic tissues. However, owing to the semiquantitative nature of the telomerase assay and other factors that might influence the level of telomerase activity detected, such as heterogeneity of trophoblastic tissues in the specimens or the presence of a telomerase inhibitor, no direct comparison of telomerase activities among individual trophoblastic tissues was made in this study.

The trophoblastic tissues were classified into those with positive or negative telomerase activity and are summarised in table 1 , together

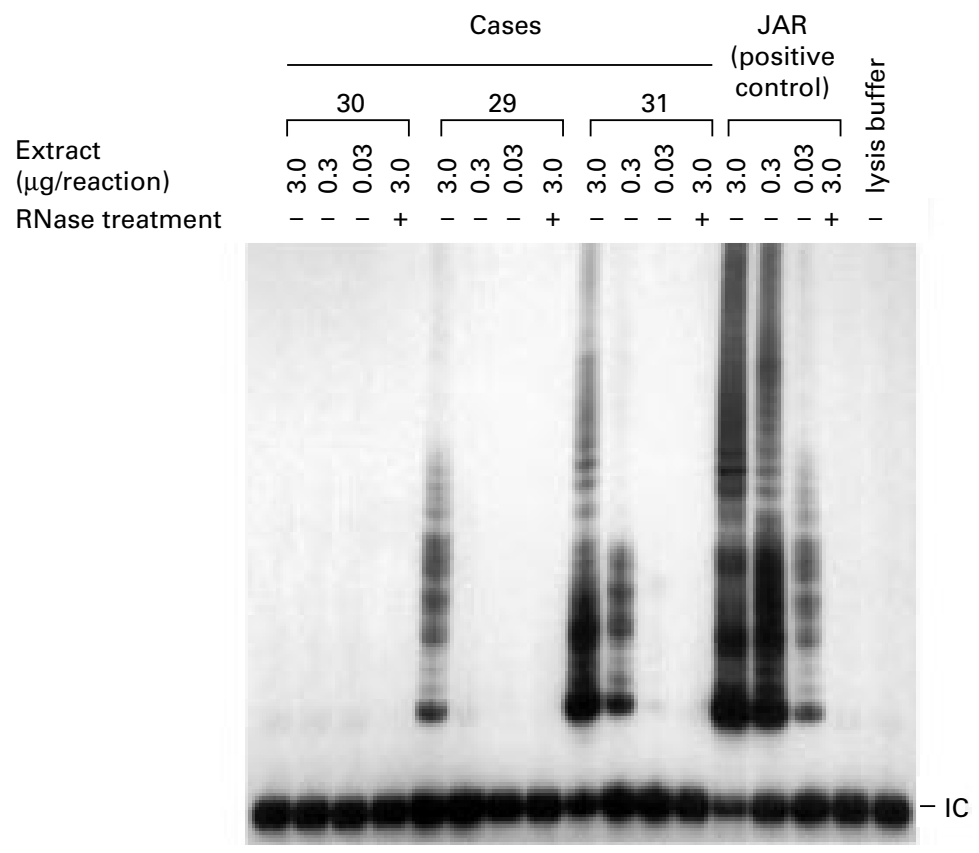

Figure 1 Telomerase activity in trophoblastic tissues. Telomerase activity was assayed at three concentrations of the telomerase extract $(3 \mu \mathrm{g}, 0.3 \mu \mathrm{g}$, and $0.03 \mu \mathrm{g}$ of protein per reaction). RNase was included in each case to ensure the specificity of the telomerase assay. IC, internal control. FAR was a choriocarcinoma cell line with clear telomerase activity showed in all three dilutions of sample. Case 31 was a first trimester placenta. Case 29 was a complete mole with positive telomerase activity. Case 30 was another complete mole with negative telomerase activity.
Table 1 Telomerase activity in trophoblastic and other tissues

\begin{tabular}{lrr}
\hline & \multicolumn{2}{l}{ Telomerase activity } \\
\cline { 2 - 3 } Tissue & Negative & Positive \\
\hline Placenta & & \\
$\quad$ Early $(<20$ weeks) $(\mathrm{n}=30)$ & 19 & 11 \\
$\quad$ Term $(\mathrm{n}=5)$ & 4 & 1 \\
Hydatidiform mole & & 5 \\
$\quad$ Spontaneous regression & 22 & 3 \\
$\quad$ PTD with no metastasis $(\mathrm{n}=4)$ & 1 & 3 \\
$\quad$ PTD with metastasis $(\mathrm{n}=4)$ & 1 & 1 \\
Choriocarcinoma $(\mathrm{n}=1)$ & & \\
Choriocarcinoma cell lines & & 1 \\
$\quad$ JAR & & 1 \\
$\quad$ JEG3 & & 2 \\
Ovarian carcinoma $(\mathrm{n}=2)$ & & 2 \\
Breast carcinoma $(\mathrm{n}=2)$ & &
\end{tabular}

PTD, persistent trophoblastic disease.

with their clinicopathological features. Positive telomerase activity was defined as the detection of strong laddering signals in at least one of the three concentrations of extract $(3 \mu \mathrm{g}, 0.3 \mu \mathrm{g}$, and $0.03 \mu \mathrm{g}$ protein per reaction). Negative telomerase activity was defined by the absence of clear laddering signals in all the three concentrations.

Telomerase activity was observed in 12 of 35 cases of placentas (34.3\%). It was detected at a higher frequency in early placentas $(36.7 \% ; 11$ positive cases out of 30) compared with term placentas $(20 \%$; one positive case out of five). However, the difference was not statistically significant $(p<0.05$; Fisher exact test, two tailed). In hydatidiform moles, telomerase activity was detected in 11 of 35 cases $(31.4 \%)$, which was not significantly different from the frequency detected in placental tissues $(34.3 \%)$. However, a higher frequency of telomerase activation was detected in hydatidiform moles which developed persistent trophoblastic disease (75\%; three of four cases) compared with those which regressed spontaneously (18.5\%; five of 27 cases). The difference was statistically significant $(\mathrm{p}<0.01$; Fisher exact test, two tailed). The frankly malignant tissues, which included one choriocarcinoma tissue, two choriocarcinoma cell lines, two ovarian carcinomas, and two breast carcinomas, were all positive for telomerase activity.

\section{Discussion}

Telomere shortening may signal cessation of cell division and trigger cell senescence. Maintenance of telomeric length is essential in sustaining continuous cell proliferation. Telomerase activity is commonly activated to maintain the telomeric length in immortal cells. ${ }^{1}$ Telomerase activation has been demonstrated in many types of human tumours, including those developing in breast, ${ }^{5}$ nasopharynx, ${ }^{6}$ stomach, ${ }^{9}$ prostate, ${ }^{10}$ urinary bladder, ${ }^{11}$ skin, ${ }^{12}$ cervix, ${ }^{7}$ and endometrium. ${ }^{13}$ These findings suggest that telomerase activation is a crucial step in human carcinogenesis. In tumours of the breast, stomach, and urinary bladder, a positive correlation between telomerase activity and clinical stage or pathological grading of the tumours has been shown. ${ }^{5911}$ Moreover, increased telomerase activity has also been found 
to be associated with poor prognosis in gastric carcinoma, ${ }^{9}$ meningioma, ${ }^{14}$ hepatocellular carcinoma, ${ }^{15}$ neuroblastoma, ${ }^{16}$ and leukaemia. ${ }^{17}$ These findings suggest that high levels of telomerase may impart a selective growth advantage in tumour cells, probably thorough stabilisation of telomeres. Lack of correlation between telomerase activity and clinicopathological features has also been reported, ${ }^{18}{ }^{19}$ which may be related to the difficulties involved in accurate quantitation of telomerase activity, as well as the purity of cancer cells in the surgical specimens. Very few studies have been reported on telomerase activation in trophoblastic diseases. ${ }^{2021}$

As with observations reported in other malignant tumours, the choriocarcinoma sample and the two choriocarcinoma cell lines showed strong telomerase activity. A few cases of hydatidiform mole also showed positive telomerase activity. In fact those cases which later developed into persistent trophoblastic disease and especially those that metastasised tended to have a higher likelihood of telomerase activation. Since telomerase activation plays an important role in sustaining continuous cell division in tumour growth, ${ }^{22}$ activation of telomerase in hydatidiform mole may facilitate the development of persistent disease. Further study with a larger sample size is, however, necessary to confirm this observation.

We detected telomerase activation in placental tissues, particularly those at an early gestational stage. In another recent study, a higher frequency of telomerase activity was also detected in early placentas compared with term placentas. ${ }^{21}$ The mechanisms of telomerase expression in the placenta are unclear but may be related to proliferative activity in the early placenta, which is important for invasion and implantation. In endometrial lesions $\mathrm{s}^{13}$ and human astrocytomas, ${ }^{24}$ it has already been shown that telomerase expression is related to proliferative activity. Wright et al reported that telomerase activity was present in various fetal tissues but not in the neonate. ${ }^{25}$ They speculated that telomerase activity may be derived from stem cells present in various tissues and is required for organogenesis. Using proliferation markers in placental tissues, we have previously shown extensive proliferation in cytotrophoblast which may function as stem cells in placentas. ${ }^{26}{ }^{27}$ Telomerase activity has also been found in haematopoietic and epithelial tissues. $^{28-30}$ Our present findings support the postulate that, besides tumours or immortalised cell lines, normal somatic cells with stem cell characteristics can express telomerase activity. The telomerase activity observed in the placenta may thus be derived from the stem cell population of trophoblasts. The higher frequency of telomerase activation in early placentas may be related to their higher proliferation rate compared with term placentas. ${ }^{26} 27$ Telomerase activity is downregulated during differentiation of cells. ${ }^{31}{ }^{32}$ This may explain the marked reduction in activity reported in late placenta ${ }^{21}$ and may be related to the differentiation of the placenta into mature villi which have reduced proliferative activity.
The expression of telomerase activity in normal placentas may be related to other factors. While peripheral blood lymphocytes are low in telomerase activity, reactive lymphocytes in tissues may express it. ${ }^{28} 33$ Hence lymphocytic infiltration in the placental tissue is another possible source of telomerase. The method used in the extraction of telomerase involved homogenisation of the placental tissue, which prevents identification of the cellular origin of the telomerase detected by the TRAP assay. However, all the placental tissues were examined histologically before extraction for telomerase and we only included those that had minimal contamination with infiltrating lymphocytes. The telomerase positive placental tissues in our study did not contain a significant population of lymphocytes on histological examination. On the other hand, lymphocytic infiltration has been observed in samples with negative telomerase activity, suggesting that infiltrating lymphocytes are unlikely to be the primary source of telomerase in our study. Moreover, by special techniques of isolation and preparation of trophoblasts, Kyo et al have already confirmed that the trophoblastic cells are the major source of telomerase activity in the placenta. ${ }^{20}$

It is interesting to note that similar telomerase activity was found in both hydatidiform moles and placentas in our study. In a previous study on quantitative analysis of the proliferation index in spontaneous abortion, hydatidiform mole, and choriocarcinoma, we showed that the choriocarcinoma group had a statistically higher proliferation index than spontaneous abortions and hydatidiform moles, while there was no significant difference between spontaneous abortions and hydatidiform moles. ${ }^{25}$ Apparently, hydatidiform mole, being a chromosomally abnormal placenta in nature, has a similar proliferative potential to normal placenta of similar gestational age. We compared the telomerase activation in hydatidiform mole with the expression of proliferation markers such as Ki67, but no significant correlation was observed. In another reported study using a smaller number of cases of gestational trophoblastic disease, hydatidiform mole as a group was found to have higher telomerase activity than normal villi. ${ }^{21}$ The significance of this finding remains to be confirmed by a larger sample study. Moreover, in complex tissues like the placenta or hydatidiform mole, which are composed of several cell types, accurate quantitation of telomerase activity is unlikely to be straightforward.

In some cases the trophoblastic tissues were negative for telomerase activity, including the early placentas and hydatidiform moles which developed metastases. We took the precaution of ensuring that the lack of telomerase activity was not due to the absence of hydatidiform mole in the specimen tested, since all the samples were checked histologically before extraction for telomerase. Insensitivity of the telomerase assay was also excluded by the presence of activity in the control cell lines and the carcinoma samples. The inclusion of internal control in the assay also exclude the possibility that the absence of 
telomerase was caused by the presence of inhibitor in the sample extract. The significance of this finding is not fully understood at this stage. It will be interesting to study telomeric dynamics in those placental tissues with positive telomerase activity compared with those with negative activity. Nonetheless, absence of telomerase activity has been found in some human cancers, including retinoblastoma and breast cancers. ${ }^{22} 3435$ Telomere maintenance in these immortal tumour cells may involve telomerase independent mechanisms. ${ }^{36-38}$

\section{CONCLUSIONS}

Our results show that telomerase activity was present in choriocarcinoma as well as in early placentas and hydatidiform moles. The similar pattern of telomerase expression in hydatidiform moles and placentas of early gestational age may reflect the comparable nature of the hydatidiform mole and the abnormal conceptus. On the other hand, hydatidiform moles which progressed to gestational trophoblastic disease tended to express telomerase activity more often than those which regressed spontaneously. A larger scale study is warrant to evaluate the prognostic significance of telomerase in predicting the clinical behaviour of hydatidiform mole.

This study was supported by a CRCG grant (335-046-0082) awarded by the Committee on Research and Conference Grant of the University of Hong Kong and competitive grants (10201473 and HKU 7325/97M) awarded by the Research Grant Council of the Hong Kong Government. We would like to thank Mr Andrew S K Chan for his technical assistance.

1 Kim NW, Piatyszek MA, Prowse KR, et al. Specific association of human telomerase activity with immortal cells and cancer. Science 1994;266:2011-15.

2 Feng J, Funk WD, Wang SS, et al. The RNA component of human telomerase. Science 1995;269:1236-41.

3 Mazur MT, Kurman RJ. Gestational trophoblastic disease. In: Kurman RJ, ed. Blaustein's pathology of the female genital In: Kurman RJ, ed. Blaustein's pathology of the female genital
tract, 4th ed. New York: Springer Verlag, 1994:1049-93.

4 Elston CW. Gestational trophoblastic disease. In: Fox H, ed. Elston CW. Gestational trophoblastic disease. In: Fox H, ed.
Haines $\mathcal{E} \sigma$ Taylor obstetrical and gynaecological pathology, 4th Haines $\mathcal{E}$ Taylor obstetrical and gynaecological pathology,
ed. New York: Churchill Livingstone, 1997:1597-640.

5 Hiyama E, Gollahon L, Kataoka T, et al. Telomerase activity in human breast tumors. $\mathcal{F}$ Natl Cancer Inst 1996;88:11622.

6 Cheng RYS, Yuen PW, Nicholls JM, et al. Telomerase activation in nasopharyngeal carcinomas. Br f Cancer 1998;77 456-60.

7 Zhang DK, Ngan HYS, Cheng RYS, et al. Clinical significance of telomerase activation and telomeric restriction fragment (TRF) in cervical cancer. Eur J Cancer 1999;35:154-60.

8 Cheung ANY, Sit ASY, Chung LP, et al. Detection of heterozygous XY complete hydatidiform mole by chromosome in situ hybridization. Gynecol Oncol 1994;55:386-92.

9 Hiyama E, Yokoyama T, Tatsumoto N, et al. Telomerase activity in gastric cancer. Cancer Res 1995;55:3258-62.

10 Sommerfeld HJ, Meeker AK, Piatyszek MA, et al. Telomerase activity: a prevalent marker of malignant human prostate tissue. Cancer Res 1996;56:218-22.

11 Lin Y, Miyamoto H, Fujinami K, et al. Telomerase activity in human bladder cancer. Clin Cancer Res 1996;88:116-22.

12 Taylor RS, Ramirez RD, Ogoshi $M$, et al. Detection of telomerase activity in malignant and nonmalignant skin conditions. F Invest Dermatol 1996;106:759-65.
13 Saito T, Schneider A, Martel N, et al. Proliferationassociated regulation of telomerase activity in human endometrium and its potential implication in early cancer diagnosis. Biochem Biophys Res Commun 1997;231:610-14.

14 Langford LA, Piatyszek MA, Xu R, et al. Telomerase activty in ordinary meningiomas predicts poor outcome. Hum Pathol 1997;28:416-20.

15 Tahara H, Nakanishi T, Kitamoto $\mathrm{M}$, et al. Telomerase activity in human liver tissues: Comparison between chronic liver disease and hepatocellular carcinomas. Cancer Res 1995;55:2734-6.

16 Hiyama E, Hiyama K, Yokoyama T, et al. Correlating telomerase activity levels with human neuroblastoma outcomes. Nature Med 1995;1:249-55.

17 Zhang W, Piatysek MA, Kobayashi T, et al. Telomerase activity in human myelogenous leukaemia: inhibition of telomerase activity by differentiation-inducing agents. Clin Cancer Res 1996;2:799-803.

18 Bednarek AK, Sahin A, Brenner AJ, et al. Analysis of telomerase activity levels in breast cancer: positive detection at the in situ breast carcinoma stage. Clin Cancer Res 1997;3: $11-16$.

19 Kyo S, Kunimic K, Uchibayashi T, et al. Telomerase activity in human urothelial tumours. Am f Clin Pathol 1997;107: $555-60$.

20 Kyo S, Takakura M, Tanaka M, et al. Expression of telomerase activity in human chorion. Biochem Biophys Res Commun 1997;241:498-503.

21 Nishi H, Yahata N, Ohyashiki K, et al. Comparison of telomerase activity in normal chorionic villi to trophoblastic diseases. Int f Oncol 1998;12:81-5.

22 Blasco MA, Rizen M, Greider CW, et al. Differential regulation of telomerase activity and telomerase RNA during multi-stage tumorigenesis. Nature Genet 1996;12:200-4.

23 Kyo S, Takakura M, Kohama T, et al. Telomerase activity in human endometrium. Cancer Res 1997;57:610-14.

24 Sallinen P, Miettinen H, Sallinen SL, et al. Increased expression of telomerase RNA component is associated with increased cell proliferation in human astrocytomas. Am f Pathol 1997;150:1159-64

25 Wright WE, Piatyszek MA, Rainey WE, et al. Telomerase activity in human germline and embryonic tissues and cells. Dev Genet 1996;18:173-9.

26 Cheung AN, Ngan HY, Chen WZ, et al. The significance of proliferating cell nuclear antigen in human trophoblastic disease: an immunohistochemical study. Histopathology 1993;22:565-8.

27 Cheung AN, Ngan HY, Collins RJ, et al. Assessment of cell proliferation in hydatidiform mole using monoclonal antibody MIB1 to Ki-67 antigen. $f$ Clin Pathol 1994;47: $601-4$.

28 Counter CM, Gutpa J, Harley CB, et al. Telomerase activity in normal leukocytes and in hematologic malignancies. Blood 1995;85:2315-20.

29 Harle-Bachor C, Boukamp P. Telomerase activity in the regenerative basal layer of the epidermis inhuman skin and in immortal and carcinoma-derived skin keratinocytes. Proc Natl Acad Sci USA 1996;93:6476-81.

30 Yasumoto S, Kunimura C, Kikuchi K, et al. Telomerase activity in normal human epithelial cells. Oncogene 1996;13:433-9.

31 Sharma HW, Sokoloski JA, Perez JR, et al. Differentiation of mmortal cells inhibits telomerase activity. Proc Natl Acad Sci USA 1995;92:12343-6.

32 Albanell J, Han W, Mellado B, et al. Telomerase activity is repressed during differentiation of maturation-sensitive but not resistant human tumor cell lines. Cancer Res 1996; 56:1503-8.

33 Hiyama K, Hirai Y, Kyoizumi S, et al. Activation of telomerase in human lymphocytes and in hematopoietic progenitor ells. F Immunol 1995;155:3711-15.

34 Tsao JL, Zhao Y, Lukas J, et al. Telomerase activity in normal and neoplastic breast. Clin Cancer Res 1997;3:627-31.

35 Gupta J, Han LP, Wang P, et al. Development of retinoblastoma in the absence of telomerase activity. F Natl Cancer Inst 1996;88:1152-7.

36 Langford LA, Piatyszek MA, Xu R, et al. Telomerase activity in human brain tumours. Lancet 1995;346:1267-8.

37 Strahl C, Blackburn EH. Effects of reverse transcriptase inhibitors on telomere length and telomerase activity in two immortalized human cell lines. Mol Cell Biol 1996;16:5365.

38 Rhyu MS. Telomeres, telomerase, and immortality. 7 Natl Cancer Inst 1995;87:884-94. 